\title{
Impact of Intrinsic Properties of Aggregate and Volumetric Properties of Hot Mixture Asphalt (HMA) in the Influence of the Resistance to Rutting
}

\author{
Mouhamed Lamine Chérif Aidara1, Makhaly Baํ, Alan Carter² \\ ${ }^{1}$ UFR Sciences de l'Ingénieur, Université de Thiès, Thiès, Sénégal \\ ${ }^{2}$ Ecole de Technologie Supérieure (ETS), Director of Pavement Bituminous Materials Laboratory (LCMB), Montréal, Canada \\ Email: mouhamedlamine.aidara@univ-thies.sn
}

How to cite this paper: Aidara, M.L.C. Ba, M. and Carter, A. (2020) Impact of Intrinsic Properties of Aggregate and Volumetric Properties of Hot Mixture Asphalt (HMA) in the Influence of the Resistanceto Rutting. Open Journal of Civil Engineering, 10, 187-194.

https://doi.org/10.4236/ojce.2020.103016

Received: July 3, 2020

Accepted: July 20, 2020

Published: July 23, 2020

Copyright $\odot 2020$ by author(s) and Scientific Research Publishing Inc. This work is licensed under the Creative Commons Attribution International License (CC BY 4.0).

http://creativecommons.org/licenses/by/4.0/ (c) (i) Open Access

\begin{abstract}
Several studies show that properties of Hot Mixture Asphalt (HMA) mix design materials, aggregate gradation and volumetric properties had an influence on their resistance to rutting. However, these properties do not impact in the same way this performance. For a given aggregate type, an infinity aggregate gradation type can be observed, and for each type of HMA several types of bituminous binder can be used. This article aims to measure the evolution of resistance to rutting according to the three main classes of National Cooperative Highway Research Program (NCHRP) aggregate gradation (dense-graded, fine-graded and coarse-graded). To this end, a study was conducted on the measurement of rutting resistance for eight bituminous mixtures manufactured with two bitumen types and two types of manufacturing aggregates. The results showed that there is a priority order of these different parameters on the influence of the resistance to rutting. This highlights a competition between the properties of aggregate and type of granular skeleton. Indeed, for the same type of aggregate, asphalt binder type first impacts resistance to rutting of the HMA followed by aggregate gradation, volumetric properties of the mix and finally by the angularity of the aggregates. However, this order cannot be fixed and can depend of the intensity of each parameter.
\end{abstract}

\section{Keywords}

Aggregate Gradation, HMA, Rutting, Basalt, Quartzite 


\section{Introduction}

Rutting generally refers to permanent deformation phenomena of the transverse profile of the roadway, which appear and grow as a result of traffic [1] [2]. The impact on the aggregate resistance to rutting of asphalt mixtures is explained by the material properties of formulations and the repeat of the traffic loads (accumulation phenomenon of the permanent deformation) [3] [4]. The properties of the mix design materials are specified for the bitumen by rheological tests (DSR) [5] or empirical test (Penetration test). Vanelstraete and Francken [6] showed that the permanent deformation measured by dynamic triaxial creep tests for a given bituminous mixture decreases with the rigidity of the bituminous binder used. Grimaux and Hiernaux [7] showed too that the resistance to rutting equipment of Road and Bridge laboratory Material (RBLM), generally increases in the presence of an increase in the hardness of the binder. A significant share of responsibility is granted to aggregate properties as angularity, percentage of fine particle and Nominal Maximum Aggregate Size (NMAS). Since aggregates make up entre $80 \%$ and $90 \%$ of the total volume or $94 \%$ to $95 \%$ of the mass of HMA, the quality of the aggregate significantly influences pavement performance [8]. Indeed, increased angularity causes an increase in rutting. On the other hand, another parameter to an important influence on the resistance to rutting of asphalt mixtures is aggregate gradation. However, for the same NMAS may have infinity of aggregate gradation, and for the same skeleton more value of angularity can be observed. This gives quite contrasting results from one study to another. El-Mamlouk and Basyouny [9] claimed that the coarse-graded HMA with great NMAS is more resistant to permanent deformation than fine-graded asphalt mixture. Stakston and Bahia [10] have shown that the resistance to rutting of asphalt mixtures largely depended on the aggregate gradation. Cross and Brown ([11]) on the other hand found that it's angularity of fine aggregates that have a significant influence on the resistance to rutting and not the aggregate gradation. Manal and Attia [12] claimed that rutting resistance of asphalt paving mixes is affected by the type of aggregate and type of gradation. The diversity of results implies the existence of an interaction between the following parameters: binder stiffness, type of aggregate gradation, intrinsic and manufactured properties and volumetric properties of HMA. Indeed all the conclusions listed above are valid only if apart from the properties of mixtures considered in the comparison of performance between mixtures, all other remaining properties are constant. This is rarely the case between two bituminous mixtures. In this article a first approach to this interaction will be sought through the measurement of the resistance to rutting of bituminous mixtures with eight HMA manufactured with three classes of granularity granular skeletons [5]. These asphalt mixtures are manufactured with two types of aggregates (basalt and quartzite) and two types of asphalt binder (PG76-16 and PG 70-16), having substantially the same zeta potential and different flattening coefficients different fraction $8 / 16$ 


\section{Methodology}

\subsection{The Flattening Coefficient}

The flattening coefficient test [1] [5] [13] of aggregates is used to characterize the form of aggregates whose size is between 4 and $40 \mathrm{~mm}$ and to monitor the regularity of gravel supplies during construction project. A rubble unfavorable shape (flat or elongated) has a high flattening coefficient (20\% to $40 \%)$. A rubble favorable shape (spherical, cubic or nodular) has a flattening coefficient generally between $5 \%$ and $20 \%$. The form of an aggregate is defined by three main dimensions:

- Length L: the biggest gap of a couple of parallel tangent planes;

- Thickness E : the smallest gap of a couple of parallel tangent planes;

- Coarseness G: size of the minimum square mesh through which the element. The lower the flattening coefficient is, the lower the angularity and the percentage of flat and elongated particles will be.

\subsection{Aggregate Gradation Concept}

The granular skeleton is the initial mixture of the various fractions of aggregates prior to impregnation with hot bitumen during the mix design of asphalt concretes. Whatever the method of mix design used aggregate gradation of asphalt concretes can be presented in four types of granularity [5]:

- Fine-graded aggregate mixture;

- Dense-graded aggregate mixture;

- Coarse-graded aggregate mixture;

- Gap-graded aggregate mixture.

However, all gradations do not have the same density. The maximum density (Figure 1) that may have an aggregate gradation is calculated by the following formula (Equation (1)):

$$
\% \mathrm{PMD}=\left(\frac{d}{D}\right) \times 100 \%
$$

With:

$\% \mathrm{PMD}=$ Percentage of PMD from the maximum density for a size of sieve; $d=$ dimension of the respective sieve $(\mathrm{mm})$;
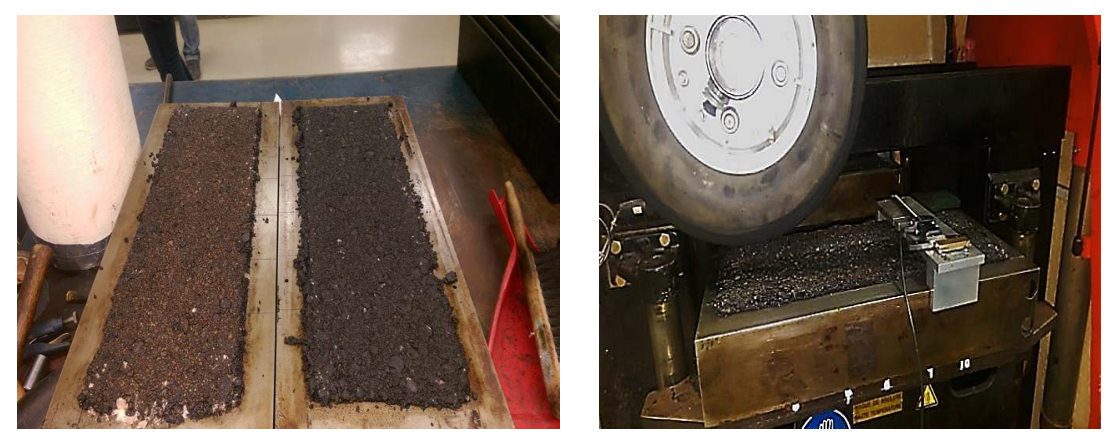

Figure 1. RBLM Rutting test equipment. 
$D=$ maximum dimension of sieves $(\mathrm{mm})$;

NB: PMD is calculated for each screen included in the particle size.

\subsection{Rutting Test Method}

This test method falls into the category of simulation tests method under repeated loading [1]. The solicitation approaches stresses encountered in situ but given the complexity of the process does not allow the determination of an intrinsic property of the material. It tracks for stress conditions used, the evolution of the deformation depending on the repetition of wheel load (Francken and Verstraeten 1995). During the rutting test, the resistance to permanent deformation of the asphalt concretes is measured on asphalt concretes plates on the LCPC rutting (Figure 1). This resistance is translated by measuring the depth wheel imprints on the coated converted to percent of rutting. These measurements are made between 1000 and 30,000 cycles.

\subsection{Experimental Plan}

Eight mixtures were made according to French mix design method [1]. These different mixtures were as follows (Table 1) (Figure 2):

- Three ESG 14 from a mixture of quartzite aggregate with quartzite and PG 70-16 bitumen grade, including a dense-graded (GDD), a coarse-graded (GDC) and a fine-graded (GDF) mixtures;

Table 1. Some characteristics of HMA studied.

\begin{tabular}{|c|c|c|c|c|}
\hline \multirow{2}{*}{$\begin{array}{c}\text { Mix } \\
\text { composition }\end{array}$} & $\begin{array}{l}\text { ESG-14 } \\
\text { GDD }\end{array}$ & $\begin{array}{c}\text { ESG-14 } \\
\text { GDF }\end{array}$ & $\begin{array}{c}\text { ESG-14 } \\
\text { GDC }\end{array}$ & $\begin{array}{c}\text { ESG-14 } \\
\text { BDC }\end{array}$ \\
\hline & $\%$ in HMA & $\%$ in HMA & $\%$ in HMA & $\%$ in HMA \\
\hline Aggregates $0 / 3 \mathrm{~mm}$ & 55.05 & 61.62 & 49.4 & 30.53 \\
\hline Aggregates $3 / 8 \mathrm{~mm}$ & 11.39 & 18.96 & 23.75 & 29.58 \\
\hline Aggregates 8/14 mm & 28.48 & 14.22 & 21.85 & 35.3 \\
\hline \multirow{3}{*}{$\begin{array}{c}\text { Bitumen } \\
\text { content (\%) }\end{array}$} & 5.08 & 5.2 & 5.00 & 4.59 \\
\hline & PG 70-16 & PG 70-16 & PG 70-16 & PG 70-16 \\
\hline & ERES & ERES & ERES & ERES \\
\hline \multirow[t]{2}{*}{ Mix composition } & $\begin{array}{c}\text { BBME } \\
0 / 14 \mathrm{~mm} \\
\text { (Basalt) }\end{array}$ & $\begin{array}{c}\text { ESG-14 } \\
\text { BDD }\end{array}$ & $\begin{array}{c}\text { EME 0/14 mm } \\
\text { (basalt) }\end{array}$ & $\begin{array}{c}\text { ESG-14 } \\
\text { BDF }\end{array}$ \\
\hline & $\%$ in HMA & $\%$ in HMA & $\%$ in HMA & $\%$ in HMA \\
\hline Aggregates $0 / 3 \mathrm{~mm}$ & 32.00 & 47.53 & 43.00 & 56.94 \\
\hline Aggregates $3 / 8 \mathrm{~mm}$ & 24.00 & 14.26 & 22.00 & 18.98 \\
\hline Aggregates 8/14 mm & 39.10 & 33.27 & 29.40 & 18.98 \\
\hline \multirow{3}{*}{$\begin{array}{c}\text { Bitumen } \\
\text { content (\%) }\end{array}$} & 5.15 & 4.94 & 5.00 & 5.11 \\
\hline & PG 76-16 & PG 70-16 & PG 76-16 & PG 70-16 \\
\hline & Thermocotank & ERES & Thermocotank & ERES \\
\hline
\end{tabular}




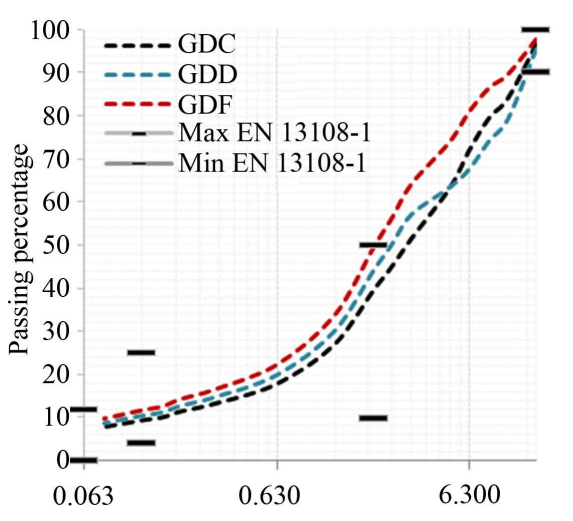

(a)

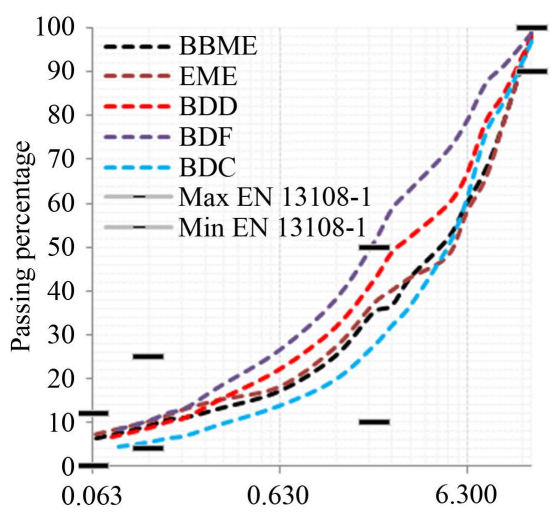

(b)

Figure 2. HMA gradation of used mixtures. (a) Sieve diameters (mm); (b) Sieve diameters $(\mathrm{mm})$.

- Three ESG 14 from a mixture of with basalt aggregate and PG 70-16 bitumen grade, including a dense-graded (BDD), a coarse-graded (BDC) and a fine-graded (BDF) mixtures ;

- A BBME and a EME coarse graded from a mixture of basalt aggregate with PG 76-16 bitumen grade.

These different types of gradation (Figure 2) will allow to measure the influence of different variations they bring in asphalt mixtures studied such as the type of bitumen, percentage binder content, etc.

Table 2 shows the intrinsic and manufacturing properties of mixtures studied.

\section{Analysis and Interpretation of Results}

Analysis of Figure 3, which shows the evolution of the percentage of rutting of mixtures studied according to the number of cycle shows that coarse-graded mixtures (EME, BBME, BDC and GDC) are more resistant to rutting than dense-graded and fine-graded mixtures. In fact, these mixtures are very rich in coarse particles with fractions of $3 / 14 \mathrm{~mm}$ greater than $45.6 \%$ by volume percentage. This is also confirmed by the fact that the mixture of basalt (BDC with $60.11 \%$ of $3 / 14 \mathrm{~mm}$ ) is more resistant to rutting that quartzite mixture (GDC with $45.6 \%$ of $3 / 14 \mathrm{~mm}$ ) because it is coarser. This confirms the work of El-Mamlouk and Basyouny [9] and Stakston and Bahia [10].

Following the same logic, the BBME with $63.1 \%$ of $3 / 14 \mathrm{~mm}$ should be stronger than the BDC and EME (51.4\% of $3 / 14 \mathrm{~mm}$ ) less resistant. This is however not the case because the EME mixture is stronger than the two latter mixtures. Indeed, the superiority to BDC can be explained by the fact that the EME is formulated with harder grade bitumen (PG 76-16 as for BBME) than the BDC (PG 70-16) and with respect to BBME the difference is negligible. This confirms the work of Francken and Verstraeten [6] and Grimaux and Hiernaux [7]. Indeed, a bituminous mixture rich in aggregates, with a low binder content and a high percentage of void exhibits good resistance to rutting (stability) but 


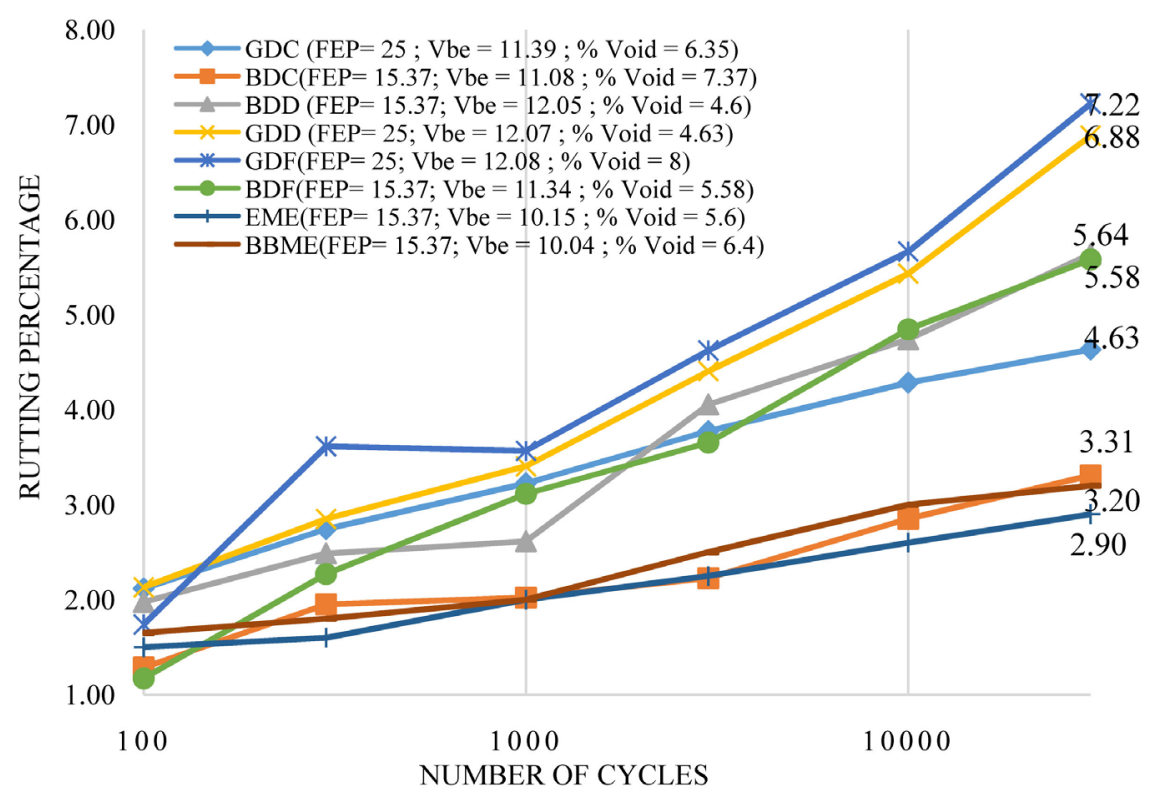

Figure 3. Evolution of rutting test results on HMA. Vbe = volume of effective asphalt binder; \%Void = Air void content; FEP = Percentage of Flat and Elongated Particles.

Table 2. Aggregates asphalt and concrete properties.

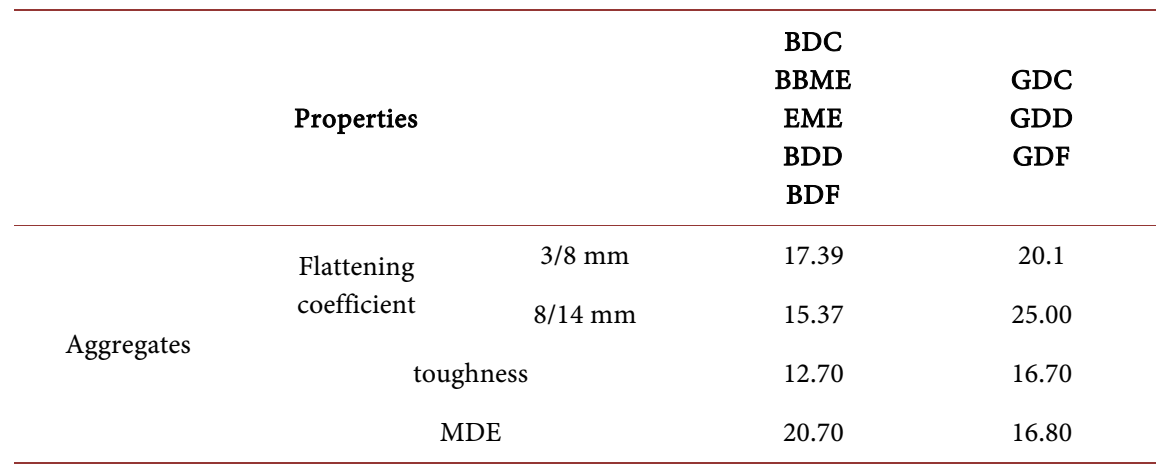

poor fatigue resistance (durability) [6]. Its implementation is more difficult [6]. Mixtures BDD and BDF have a considerable difference in void percentage with $8.05 \%$ and $4.6 \%$ respectively (almost double). Thus equality observed on rutting resistance could be linked to compensation for the BDF due to its larger void percentage. Mixtures of quartzite present in turn substantially equal void percentages, thus the action of the granular mixture and $\mathrm{V}_{\mathrm{be}}$ is the main for the latter. On the other hand, the logic of this result seems not follow other mixtures because the remaining basalt mixtures (BDD $47.53 \%$ of $3 / 14 \mathrm{~mm}$ and BDF $37.96 \%$ of $3 / 14 \mathrm{~mm}$ ) are more resistant to rutting mixtures quartzite (GDD $39.87 \%$ of $8 / 14 \mathrm{~mm}$ and GDF $33.18 \%$ of $8 / 14 \mathrm{~mm}$ ) and the BDD is less resistant than the GDC and yet richer in coarse particles with a better shape and void percentage. This result is explicit by another parameter called Vbe. The effective asphalt binder content (Vbe) is defined as the total binder content of bituminous mixture less the content of binder absorbed by the aggregates. Figure 3 shows 
that among these bituminous mixtures, the GDC has the lowest Vbe (as a percentage of volume). Although BDD and GDD are more resistant to rutting that the BDF and GDF respectively, the conclusion does not apply between BDF and GDD.

It should be more resistant to rutting, which is not the case. This result can be explained by another parameter called flattening coefficient (FC). Indeed, basalt aggregates with a FC of 17.39 and 15.37 were better than the crushed quartzite aggregate with a FC of 25 (Figure 4). If all aggregates used are road aggregates (NF EN 13043), the work of Manal and Attia are unaudited.

The difference between the rutting of mixtures studied seems to be effective as from 10,000 cycles. Indeed, causing permanent deformation is plastic nature and lies mainly in the rearrangement of the granular skeleton relative displacements of each grain relative to the other by translations and rotations (Figure 4) [1].

\section{Conclusion}

This study showed that there is a competition between the intrinsic properties of the HMA mix design materials and volumetric properties of asphalt mixtures in the influence of the resistance to rutting of HMA. Among the properties that influence the resistance to rutting, the rigidity of the asphalt binder showed more impact, followed by the class of aggregate gradation, followed by the volumetric properties of the mixture (percentage of void and Vbe) and finally by angularity of coarse aggregates specified by flattening coefficient. This order can not necessarily be fixed for the other type of mixture. However, an important hypothesis remains to be verified, the angularity of fine aggregates. Indeed, studies have shown that it's the angularity of fine aggregates and not the aggregate gradation of mixtures which significantly influenced rutting of asphalt mixtures.

\section{Acknowledgements}

The authors would like to acknowledge the research group of the "Ecole de Technologies Supérieure" of Montréal.

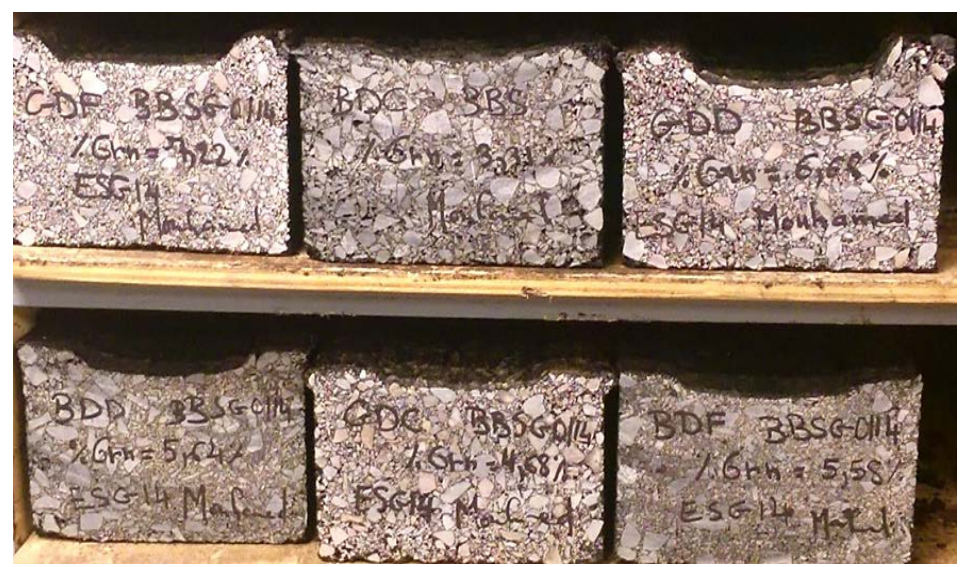

Figure 4. Rearrangement of the granular skeleton after 30,000 sollicitations cycles. 


\section{Conflicts of Interest}

The authors declare no conflicts of interest regarding the publication of this paper.

\section{References}

[1] Di Benedetto, H. and Corté, F. (2005) Materials (Vol. 2). H. Science, Edition, Lavoisier, Lyon.

[2] Meunier, M. (2012) Development of a Predictive Tool for the Behavior of Pavement Rutting, Construction Engineering. PhD Thesis, Montréal, Ecole de Technologie Supérieure.

[3] Neiffar, M., Di Benedetto, H. and Dongmo, B. (2003) Permanent Deformation and Complex Modulus: Two Different Characteristics from a Unique Test. RILEM Symposium PTEBM 03, Partie 1, Zurich, 316-323.

[4] Marks, V.J., Monroe, R.W. and Adam, J.F. (1990) Effects of Crushed Particles in Asphalt Mixtures. Transportation Research Board.

[5] Advanced Asphalt Technologies (AAT) (2011) A Manual for Design of Hot Mix Asphalt with Commentary. NCHRP Report 673. Manual, National Research Council, Transportation research Board, Washington, DC.

[6] Verstraeten, J. (1995) Bituminous Mixtures with High Resistance to Rutting. Technical Report, Association Internationale Permanente des Congrès de la Route (AIPCR), Référence 08.03.B, 160 p.

[7] Grimaux, J.-P. and Hiernaux, R. (1977) Utilization of Rutting LPC Type. Bulletin des Laboratoires des Ponts et Chaussées Décembre Spécial V, 165-172.

[8] Young-Rak, K., et al. (2009) Effects of Aggregate Angularity on Mix Design Characteristics and Pavement Performance. Mid-America Transportation Center, University of Nebraska-Lincoln.

[9] El-Basyouny, M.M. and Mamlouk, M.S. (1999) Effect of Aggregate Gradation on Rutting Potential of Superpave Mixes Paper No. 99-0602. 78th Annual Meeting of the Transportation Research Board, Washington D.C., 176 p.

[10] Stakston, A.D. and Bahia, H. (2003) The Effect of Fine Aggregate Angularity, Asphalt Content and Performance Graded Asphalts on Hot Mix Asphalt Performance, University of Wisconsin-Madison, Department of Civil and Environmental Engineering, Submitted to Wisconsin Department of Transportation, Division of Transportation Infrastructure Development, Research Coordination Section, WisDOT Highway Research Study 0092-45-98.

[11] Cross, S.A. and Brown, E.R. (1992) Selection of Aggregate Properties to Minimize Rutting of Heavy-Duty Pavements. In: Meininger, R.C., Ed., Effect of Aggregate and Mineral Fillers on Asphalt Mixture Performance, ASTM, STP 1147.

[12] Manal, A. (2013) Impact of Aggregate Gradation and Type on Hot Mix Asphalt Rutting in Egypt. International Journal of Engineering Research and Applications (IJERA), 3, $10 \mathrm{p}$.

[13] NF EN 933-3 (1997) Tests for Geometrical Properties of Aggregates-Part 3 Determination of the Shape of Aggregates-Flattening Coefficient. French Association for Standardization. 